\title{
Large scale surveys for cetaceans: line transect assumptions, reliability of abundance estimates and improving survey efficiency - a response to MacLeod
}

Philip S Hammond ${ }^{\mathrm{a}^{*}}$, Kelly Macleod ${ }^{\mathrm{b}}$, Per Berggren ${ }^{\mathrm{c}}$, David L Borchers ${ }^{\mathrm{d}}$, Louise Burt ${ }^{\mathrm{d}}$, Ana Cañadas $^{\mathrm{e}}$, Geneviève Desportes ${ }^{\mathrm{f}}$, Greg P Donovan ${ }^{\mathrm{g}}$, Anita Gilles ${ }^{\mathrm{h}}$, Douglas Gillespie ${ }^{\mathrm{a}}$, Jonathan Gordon $^{\mathrm{i}}$, Russell Leaper ${ }^{\mathrm{j}}$, Kristina Lehnert ${ }^{\mathrm{h}}$, Mardik Leopold ${ }^{\mathrm{k}}$, Phil Lovell ${ }^{\mathrm{a}}$, Nils Øien ${ }^{1}$, Charles GM Paxton $^{\mathrm{d}}$, Vincent Ridoux ${ }^{\mathrm{m}}$, Emer Rogan ${ }^{\mathrm{n}}$, Filipa Samarra ${ }^{\mathrm{a}}$, Meike Scheidat ${ }^{\mathrm{k}}$, Ursula Siebert ${ }^{\mathrm{h}}$, Henrik Skov $^{\mathrm{o}}$, René Swift ${ }^{\mathrm{a}}$, Mark L Tasker ${ }^{\mathrm{b}}$, Jonas Teilmann ${ }^{\mathrm{p}}$, Olivier Van Canneyt ${ }^{\mathrm{q}}$, José Antonio Vázquez ${ }^{\mathrm{r}}$

${ }^{a}$ Sea Mammal Research Unit, Scottish Oceans Institute, University of St Andrews, St Andrews, Fife KY16 8LB, UK.

${ }^{\mathrm{b}}$ Joint Nature Conservation Committee, Inverdee House, Baxter Street, Aberdeen AB11 9QA, UK.

${ }^{c}$ School of Marine Science and Technology, Dove Marine Laboratory, Newcastle University, Cullercoats, North Shields, Tyne and Wear, NE30 4PZ, UK.

${ }^{\mathrm{d}}$ Centre for Research into Ecological and Environmental Modelling, Buchanan Gardens, University of St Andrews, St Andrews, Fife KY16 9LZ, UK.

e Alnilam Investigación y Conservación, Cándamo 116, 28240 Hoyo de Manzanares, Madrid, Spain.

${ }^{\mathrm{f}}$ GDnatur, DK-5300 Kerteminde, Denmark.

${ }^{\mathrm{g}}$ International Whaling Commission, The Red House, 135 Station Road, Impington, Cambridge CB4 9NP, UK.

${ }^{\mathrm{h}}$ Institute for Terrestrial and Aquatic Wildlife Research (ITAW), University of Veterinary Medicine Hannover Foundation (TiHo), Werftstr. 6, 25761 Büsum, Germany.

${ }^{\mathrm{i}}$ Ecologic, 7 Beechwood Terrace West, Newport on Tay, Fife DD6 8JH, UK.

${ }^{\mathrm{j}}$ International Fund for Animal Welfare, 87-90 Albert Embankment, London SE1 7UD, UK.

${ }^{\mathrm{k}}$ IMARES - Institute for Marine Resources and Ecosystem Studies, PO Box 167, 1790 AD Den Burg, The Netherlands.

${ }^{1}$ Institute of Marine Research, PO Box 1870 Nordnes, N-5817 Bergen, Norway.

${ }^{\mathrm{m}}$ Littoral, Environnement et Sociétés, UMR 6250, Université de La Rochelle / CNRS, 2 rue Olympe de Gouges, 17032 La Rochelle, Cedex France.

${ }^{\mathrm{n}}$ School of Biological, Earth and Environmental Sciences, University College Cork, Distillery Fields, North Mall, Cork, Ireland.

${ }^{\circ}$ DHI, Agern Alle 5, DK-2920 Hørsholm, Denmark.

${ }^{\mathrm{p}}$ Department of Bioscience, Aarhus University, Frederiksborgvej 399, DK-4000, Roskilde, Denmark.

${ }^{\mathrm{q}}$ Centre de Recherche sur les Mammifères Marins, Observatoire Pelagis, UMS 3462, Université de La Rochelle, CNRS, Pôle Analytique, 5 allées de l'Océan, 17000 La Rochelle, France.

${ }^{\mathrm{r}}$ Sociedad Española de Cetáceos, Cabeza de Manzaneda 3, Algeciras, Pelayo, 11390, Spain.

* Corresponding author: Email: psh2@st-andrews.ac.uk; Tel: +44 (0)1334463222; Fax: +44 (0) 1334463443

Keywords: line transect sampling; survey design; abundance estimation; cetacean; conservation; EU Habitats Directive 
MacLeod (2014) criticises the design of the 2005 SCANS-II survey of cetaceans in European Atlantic waters (Hammond et al. 2013) for failing to assess some underlying assumptions of line transect (distance) sampling. The basis of his argument can be summarised as: white-beaked dolphins are patchily distributed over the SCANS-II survey area; the survey design does not reflect this distribution; therefore this violates distance sampling assumptions. He concludes that the estimates for white-beaked dolphin "should not be used for any conservation purpose, including assessments of the conservation status of this species. Similar issues may also exist with the abundance estimates of other species generated from the SCANS-II surveys". The conclusions are strong but the basic argument presented to support these statements is flawed.

MacLeod (2014) states that the SCANS-II surveys "were designed based on the spatial distribution of a single species". This is incorrect. As stated in Hammond et al. (2013), our survey blocks were chosen primarily for logistical reasons and transect lines within them were generated using a systematic design with random starting points designed to give equal coverage probability within blocks. The random component of transect placement is fundamental to any line transect survey. Equal coverage probability survey designs, as implemented in the SCANS-II survey, are used specifically to avoid making any assumptions about the distribution of animals, which is typically unknown, and to ensure that estimates of abundance are design-unbiased.

MacLeod (2014) also draws attention to the known presence of white-beaked dolphins in survey block B in which no animals were detected on the SCANS-II survey, leading to abundance being estimated (not assumed, as he states) to be zero. He interprets this as evidence of "the inappropriateness of the SCANS II survey design for estimating the abundance of a species with a patchy and discontinuous distribution".

If "inappropriateness" is replaced by "inefficiency", and "at small spatial scales" is added as a qualifier, we agree. Large scale surveys like SCANS-II have low coverage probability and are not designed to capture small-scale features in distribution and abundance, especially in areas of low abundance and/or patchy distribution. Uncertainty in the abundance estimates given in Hammond et al. (2013) is reflected in the estimated coefficients of variation, which are high for individual survey blocks; fine scale inferences should not be made from the results, as stated in the paper. Local populations of cetaceans can be monitored at such smaller scales using appropriate techniques (e.g. Cheney et al. 2013). These points neither invalidate the design-based estimates of abundance in Hammond et al. (2013), nor preclude reliable inference at a large spatial scale, the purpose of our surveys.

If, as MacLeod (2014) describes for the white-beaked dolphin, there is prior knowledge of distribution of a particular species then survey efficiency and precision of abundance estimates for this species would be improved if survey blocks could be created to minimise variation in density within blocks. Such focused stratification can be good practice and can potentially provide more precise estimates of abundance. However, in multispecies survey such as SCANS-II this is difficult to achieve for all species because the most efficient selection of survey blocks for one species is unlikely to be the most efficient for others. Nonetheless, as knowledge of cetacean distribution improves through small scale surveys, such as those alluded to by Macleod (2014), it will be important to take this information into account in designing future large scale surveys; this will be done in planning for a potential SCANS-III survey in 2016.

Macleod (2014) states that, for the white-beaked dolphin, "the discrepancies between the SCANS-II abundance estimates and other, more extensive, survey data for individual survey blocks are readily identifiable" but presents no information to support this. To our knowledge, there are no other recent estimates of white-beaked dolphin abundance in the SCANS-II area. If the more extensive survey data alluded to by MacLeod (2014) were analysed to estimate abundance, this information could also be considered by EU Member States when reporting to the European Commission under Article 17 of the Habitats Directive.

Macleod (2014) suggests that the SCANS-II data should be reanalysed using post-survey restratification. Post-stratification of data from a survey that implemented equal coverage probability 
sampling within blocks would likely violate the assumptions of the design and is inadvisable. However, model-based abundance estimation methods that relate sample density to spatially explicit environmental covariates (so-called density surface modelling) do not make the same assumptions about survey design and can potentially provide more precise estimates of abundance. Model-based methods come with their own assumptions, but such a re-analysis of SCANS-II data together with "other, more extensive, survey data" alluded to by Macleod (2014) could be an informative exercise.

We refute that the estimates of abundance in our paper are unreliable and should not be used for any conservation purpose. On the contrary, by using the necessary sampling design for unbiased estimation, large scale SCANS-type surveys and the estimates of abundance that they generate contribute important information that helps Member States meet their responsibilities with respect to cetaceans under the EU Habitats Directive and Marine Strategy Framework Directive.

\section{References}

Cheney, B, Thompson, PM, Ingram, SN, Hammond, PS, Stevick, PT, Durban, JW, Culloch, RM, Elwen, SH, Mandleberg, L, Janik, VM, Quick, NJ, Islas-Villanueva, V, Robinson, KP, Costa, M, Eisfeld, SM, Walters, A, Phillips, C, Weir, CR, Evans, PGH, Anderwald, P, Reid, RJ, Reid, JB \& Wilson, B. 2013. Integrating multiple data sources to assess the distribution and abundance of bottlenose dolphins Tursiops truncatus in Scottish waters. Mammal Review 43: 71-88.

Hammond, PS, Macleod, K, Berggren, P, Borchers, DL, Burt, ML, Cañadas, A, Desportes, G, Donovan, GP, Gilles, A, Gillespie, D, Gordon, J, Hiby, L, Kuklik, I, Leaper, R, Lehnert, K, Leopold, M, Lovell, P, Øien, N, Paxton, CGM, Ridoux, V, Rogan, E, Samarra, F, Scheidat, M, Sequeira, M, Siebert, U, Skov, H, Swift, R, Tasker, ML, Teilmann, J, Van Canneyt, O \& Vázquez, JA. 2013. Cetacean abundance and distribution in European Atlantic shelf waters to inform conservation and management. Biological Conservation 164: 107-122.

MacLeod, CD. 2014. One size does not necessarily fit all for cetacean abundance estimate survey design - Reply to Hammond et al. (2013). Biological Conservation. 